\title{
Investigation of the Effect of Microcapsule Additive on Mechanical and Physical Properties of Concrete
}

\author{
Reem T. Salmana*, Alaa A. Abdul-Hamead $\odot$, Farhad M. Othman $(1)$ \\ Materials Engineering Dept., University of Technology-Iraq, Alsina'a street, 10066 Baghdad, Iraq. \\ *Corresponding author Email: mae.19.24@grad.uotechnology.edu.iq
}

\section{H I G H L I G H T S}

- Concrete mix has been reinforced with $\mathrm{SiO}_{2}$ microcapsules to seal concrete cracks.

- Great Self-healing capacity of concrete that contain $\mathrm{SiO}_{2}$ microcapsules.

- Crack of concrete with $\mathrm{SiO}_{2}$ microcapsules was self-healed in 28 days.

\section{A R T I C L E IN F O}

Handling editor: Jawad K. Oleiwi

\section{Keywords:}

Concrete encapsulated

Self-healing, $\mathrm{SiO}_{2} \mathrm{MC}$

Mechanical properties

\author{
A B S T R A C T
}

\section{Introduction}

Over time, concrete structures are more susceptible to cracking, as we notice that small cracks have no effect on these structures, but the problem lies in the large cracks that cause the breakdown of concrete structures. These cracks will allow gases, chemicals, rain, etc. to enter, which will reduce the life of the structures and reduce the physical and mechanical properties. Structure's maintenance and rebuilding are more difficult and expensive, including labor and energy costs. In recent years, a new approach has been proposed to improve the physical and chemical properties of concrete and heal cracks. These materials can treat and improve the properties by producing precipitated crystals such as calcium carbonate [1]. There are several methods of self-healing materials, including a self-healing agent (fibers, nanocrystals, and mineral additives (i.e., stretching agents) and the other type is a self-healing agent (micro-capsules, tubes, vascular capsule, cement-coated granules, and bacteria)[2]. There are many techniques for creating capsules, from mixing to the end in complex and delicate ways. There are many challenges to this method, ranging from the ability of micro-capsules to stick without breaking during mixing, to their longevity within the base material [3]. In this work cement and silicon oxide were used as the nucleus of the microcapsule. Previous studies showed the positive effect when using silicon oxide nanoparticles as additives, according to Ali Haidari et al. [4], where adding a small amount of $\left(\mathrm{Nano} \mathrm{SiO}_{2}\right)$ to the concrete improved its compressive strength and decreased its ability to absorb water and the physical properties of concrete. In another study, Aggarwal et al. [5], it was noted that the samples containing $\left(\mathrm{Nano}_{\mathrm{SiO}}\right)$ increased the compressive strength to them with the increase of $\left(\mathrm{Nano} \mathrm{SiO}_{2}\right)$, and they noted the increase in tensile strength and durability compared to the standard sample. While the polymer material was used as a coating for the microcapsules, many researchers used polymer materials, for example: epoxy [6], PMMA [7], polyurethane [8], and polystyrene. Biqin Dong et al. [9] studied how to use polystyrene as a coating and how to release healing agents. Benoit Hilloulin et al. [10] studied the ability of microcapsules made of polystyrene shell to resist concrete mixes. The use of microcapsules is of great importance in improving many properties in addition to the ability to self-healing. Many studies have used the micro-capsule technique and have noted a positive effect in treating cracks and improving the properties. Zhengxian Yang et al. [11] used micro-capsules in the concrete mixture as the results showed the ability of micro-capsules to self-heal as well as 
an increase in resistance to bending and compression. Likewise, Wei Du et al. [12] used micro-capsules to treat concrete cracks and add an improvement in their properties. The results were evident from the ability of the micro-capsules to heal in a few periods of time. The purpose of this study is preparing a concrete mixture suitable for concrete applications that can self-repair by adding different proportions of $\mathrm{SiO}_{2}$ micro capsules, in order to observe the effect of these capsules on the efficiency of selfhealing, by studying the physical and mechanical properties of them and also to observe the slit-closing mechanism in the micro-capsule-containing samples compared to the standard sample.

\section{Experimental Part}

This work included two methods: The first is the combination of micro-capsules $\left(\mathrm{SiO}_{2} \mathrm{MC}\right)$ with concrete in different proportions $(2.5 \%)$ of cement weight, and their effect on concrete performance is studied. Second, cracks are made in the concrete and the effect of $\left(\mathrm{SiO}_{2} \mathrm{MC}\right)$ on the mechanism and healing period is studied. In this study, ordinary Portland cement of the first type is used, which is imported from the Iraqi State Cement Company. We see that the chemical analysis in Table 1 is consistent with ASTM 105. The average volume of dry used cement powder passing through a $38 \mu \mathrm{m}$ sieve.

Capsules are manufactured by a pelletizing process (fluidized bed coating). A sieving process is performed for the fine

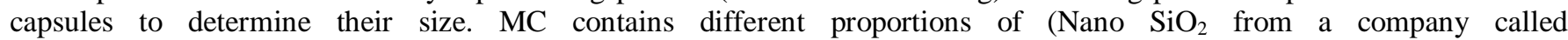
(ULTRANANOTECH.PVT. LTD) and cement) and polystyrene polymers (SIR) as shown in Table 2. Properties of (SiO $\left.{ }_{2} \mathrm{MC}\right)$ are shown in Table 3. Microcapsules are shown in Figure 1. Cement Concrete was mixed at room temperature. First, the dry concrete mixture (cement, fine aggregate certified in EN 196-1, and coarse aggregate (Al-nibaee 19/5)) was mixed, then we added microcapsules $(2.5 \%$ by weight of cement) to the concrete mix. All concrete samples have water to cement ratio (w / c) of 0.45 and a ratio of cement, fine aggregate, and coarse aggregate materials 1: 2: 4, according to (BS 1881-111: 1983), [13], with the addition of $0.6 \%$ by weight of cement from Glinume 51 superplasticizers (BASF). Before applying the concrete, to ensure easy sample extraction, the inner mold is lubricated. $100 * 100 * 100 \mathrm{~mm}$ molds were used. Plastic foil is used to cover molded samples for the first 24 hours to prevent moisture loss. After drying, they are immersed in water for various treatment periods until the time of testing. The proportions used in the formation of cement concrete are shown in Table 4.

Table 1: Cement Compound

\begin{tabular}{lll}
\hline Oxide composition & Abbreviation & \% by Weight \\
\hline Lime & $\mathrm{CaO}$ & 63.37 \\
Silica & $\mathrm{SiO}_{2}$ & 18.75 \\
Alumina & $\mathrm{Al}_{2} \mathrm{O}_{3}$ & 5.29 \\
Iron oxide & $\mathrm{Fe}_{2} \mathrm{O}_{3}$ & 4.28 \\
Sulphate & $\mathrm{SO}_{3}$ & 2.25 \\
Magnesia & $\mathrm{MgO}$ & 2.36 \\
Loss of Ignition & L.O.I. & 1.55 \\
Lime saturation factor & L.S.F. & 0.90 \\
Insoluble residue & I.R. & 1.15 \\
\hline
\end{tabular}

Table 2: The proportions of the micro-capsule contents

\begin{tabular}{lccccc}
\hline \multicolumn{6}{l}{ Capsule } \\
\hline Mix & $($ wt.\%) & Nano powder use & Nano powder $(g)$ & Cement (g) & Polymer $(g)$ \\
MS1 & 5 & $\mathrm{SiO}_{2}$ & 3 & 57 & 2 \\
MS2 & 10 & $\mathrm{SiO}_{2}$ & 6 & 54 & 3 \\
MS3 & 15 & $\mathrm{SiO}_{2}$ & 9 & 51 & 4 \\
\hline
\end{tabular}

Table 3: Typical Properties of $\mathrm{SiO}_{2} \mathrm{MC}$

\begin{tabular}{llllll}
\hline SiO2 MC & Core/Shell material & Morphology & Size & Color & $\begin{array}{l}\text { Thickness of the } \\
\text { shell }\end{array}$ \\
\hline Specification & $\begin{array}{l}\text { Nano particle SiO2 } \\
\text { (core)PS (shell) }\end{array}$ & Aspheric & $212(\mu \mathrm{m})$ & Gray & $2(\mu \mathrm{m})$ \\
\hline
\end{tabular}

Table 4: The proportions of concrete mixture in $\left(\mathrm{Kg} / \mathrm{m}^{3}\right)$ with $2.5 \% \mathrm{SiO}_{2} \mathrm{MC}$ by weight of the cement

\begin{tabular}{lllllll}
\hline Mix & $\begin{array}{c}\text { Type of } \\
\text { MC }\end{array}$ & Ages(day) & Cement & $\begin{array}{c}\text { Coarse } \\
\text { aggregate }\end{array}$ & $\begin{array}{c}\text { Fine } \\
\text { aggregate }\end{array}$ & MC \\
\hline M0 & - & $3,7,28,90$ & 280 & 560 & 1120 & - \\
M1 & MS1 & $3,7,28,90$ & 273 & 560 & 1120 & 7 \\
M2 & MS2 & $3,7,28,90$ & 273 & 560 & 1120 & 7 \\
M3 & MS3 & $3,7,28,90$ & 273 & 560 & 1120 & 7 \\
\hline
\end{tabular}




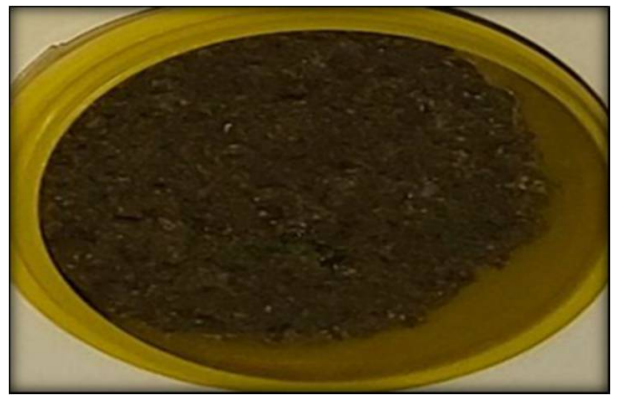

Figure 1: $\mathrm{SiO}_{2}$ Microcapsules

\section{Testing}

\subsection{Compressive Strength}

The compressive strength of the cubes was obtained by using a compacting device for concrete samples made with dimensions $(100 * 100 * 100) \mathrm{mm}$. In accordance with BS 1881-116: 1983 [14], assay was performed for each concrete sample for a period of $3,7,28$, and 90 days.

\subsection{Flexural Strength Test}

The bending test is performed using prismatic mold prepared with specified dimensions of $(75 * 75 * 300) \mathrm{mm}$, in accordance with BS 12390-5: 2009. The crack is made by means of a three-point flexural strength test. Slots of $3 \mathrm{~mm}$ deep below each prism in the center of the base were made using a circular saw to act as strength focus points. The applied speed was $0.04 \mathrm{~mm} / \mathrm{min}$. The results were recorded for ready-made concrete samples at the age of 28 days [15]. To determine the flexural strength, we used the following equation:

$$
F c t=F * I /(d 1 *(d 2) 2)
$$

Where: Fct: is the flexural strength, in $\mathrm{MPa}\left(\mathrm{N} / \mathrm{mm}^{2}\right)$;

$\mathrm{F}$ : is the maximum load, in $\mathrm{N}$.

$\mathrm{I}$ : is the distance between the supporting rollers, in $\mathrm{mm}$;

$\mathrm{d} 1$ and $\mathrm{d} 2$ : are the lateral dimensions of the specimen, in $\mathrm{mm}$.

After 28 days, the restoration of the bending strength is evaluated again ( $2 \mathrm{R})$ after healing, and an equalizer is applied:

$$
\eta \%=f c t 1 / f c t 2
$$

Where: $\eta \%$ : is the efficiency of healing.

fct 1: is maximum stress for the original sample (1st R);

fct2: is maximum stress for the sample after healing (2nd R)

Samples are removed from the water weekly to measure the width of the slit and imaging is taken over time to estimate the rate of strength recovery.

\subsection{Dry Density}

Density can be calculated according to ASTM (C642-2013) specifications, where it can be calculated after drying the sample and weighing it suspended in water and weighing it after being immersed in water for 24 hours.

Dry density can be calculated from the equation [16]:

$$
\text { Dry density }(\mathrm{g} / \mathrm{cm} 3)=[w 1 /(w 2-w 3)] * \rho w
$$

Where, W1: Mass of oven-dried sample in air, $\mathrm{g}$.

W2: Mass of surface-dry sample in air after immersion and boiling, $g$.

W3: Apparent mass of the sample in water after immersion and boiling, $\mathrm{g}$.

$\rho W$ : Density of water, which is equal to $\left(1 \mathrm{~g} / \mathrm{cm}^{3}\right)$.

\subsection{Porosity}

This test was performed according to the procedure specified in ASTM Specifications (C642-1997). The method test was similar to that of dry density test; and the porosity can be calculated by using the following equation:

$$
\text { Porosity }=[(w 2-w 1) /(w 2-w 3)] * 100 \%
$$

\subsection{Water Absorption}

Water absorption can be calculated in a similar way to calculating density (Archimedes base), except that a sample is not weighed while suspended in water. This scan is performed according to ASTM Specification (C642-1997).

water absorption in mortar samples can be calculated using the equation: 


$$
\text { Absorption of Water }=[(w 2-w 1) / w 1] * 100 \%
$$

The tests of dry density, total water absorption, and porosity were carried out in the metallurgy lab of Materials Eng. Dep./University of Technology.

\section{Results and Discussion}

\subsection{Compressive Strength}

In Figure 2 the results for the compressive strength test at ages of 3, 7, 28 , and 90 days are shown for all cubic samples. At the age of 3 days, the results of the MS and $0 \mathrm{M}$ samples showed a slight increase in strength, and all samples (reference and MS) also showed an excess of the required strength at 28 days. The improvement in strength of all samples can be attributed to the effect of the superplasticizer which, as a parameter, represents the lowest ratio of water to cement used in preparing the concrete mixture. It contains more C2S (Dicalcium Silicate) and less C3S (Tricalcium Silicate), which is highly correlated with potency at distant ages. Moreover, the $\mathrm{SiO}_{2} \mathrm{MC} 10 \%$ sample showed the highest strength at the age of 3, 7, 28, and 90 days, the decrease in strength occurs at all ages when the amount of $\mathrm{SiO}_{2} \mathrm{MC}$ exceeds $10 \%$ (percentage of added Nano powder to capsule ) which agrees with previous research [17-19].

\subsection{Dry Density}

Figure 3 shows the density test results for the tested samples containing capsules $(2.5 \%)$ by weight of cement and standard sample, where we notice an increase in density of up to $1 \%$, because of the presence of $\mathrm{SiO}_{2} \mathrm{MCs}$ in the concrete mixture that works on improving the rate of cement hydration and making denser microstructure when comparing to control samples at the same ages and then it decreases above this percentage, but the density of M2 is still higher by $(2.34,2.4,2.50083$, and $2.58) \mathrm{g} / \mathrm{cm}^{3}$ at the same ages, respectively compared to control samples [20, 21].

\subsection{Water Absorption}

Through the results of the absorption test, Figure 4 shows that the absorption results for control sample exceeded those for MS samples, from previous results, where the addition of these MCS to concrete leads to a large decrease in the water absorption and this might be due to the result of more C-S-H gel formation and reducing the pore size to the partial or total filling of pores through the physical and chemical effects of these MCS, where the addition reduced water absorption in 3days to $(0.1,0.07,0.065$, and 0.08$) \%$, respectively for mix (M0, M1, M2, and M3) [18,20,22].

\subsection{Porosity}

The results of the porosity tests for all samples more than the control samples at all ages are shown in Figure 5. The microcapsules will act as a filler material to enhance the density of the concrete, which greatly reduces the porosity of the concrete and the $\mathrm{CSH}$ gel cannot grow and it limits the growth of a dense $\mathrm{Ca}(\mathrm{OH}) 2$ crystal causing the porosity to be reduced. The porosity could be considered as an adverse property to density, so the porosity value reduction was due to the density increase. Porosity improvement ratios in 28 day was $(48.096,58.47$, and 44.636) \%, respectively with (M1, M2, and M3) $[18,20]$.

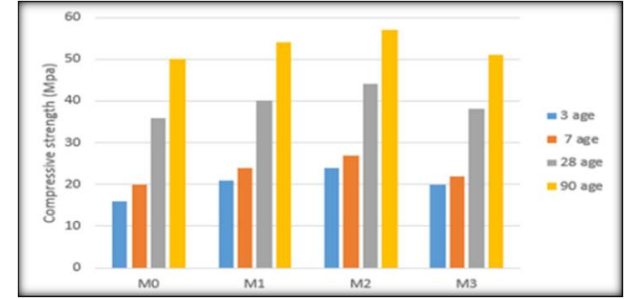

Figure 2: Compressive strength results for all samples at ages3, 7, 28, and 90 days

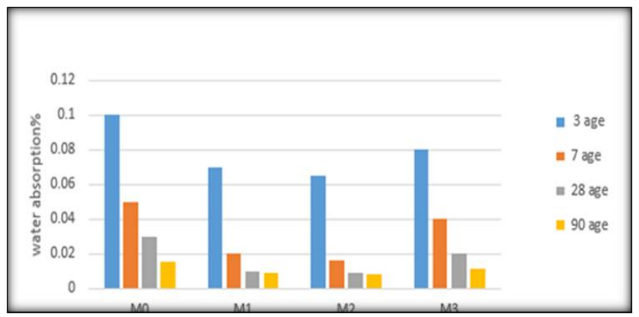

Figure 4: Water absorption percentage for all samples



Figure 3: Dry density of all samples at all ages

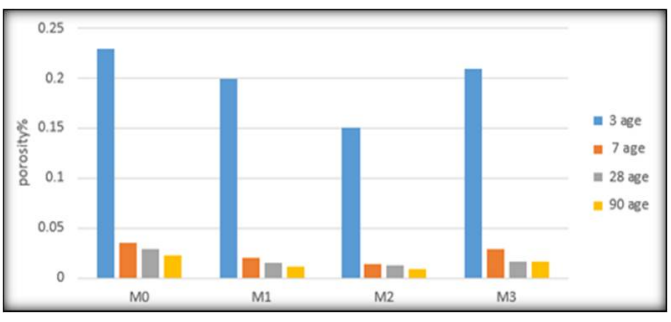

Figure 5: Porosity percentage of all samples 


\subsection{Flexural Strength}

From the compressive strength results, a ratio of $1 \%$ was adopted to predict the results of the flexural test. Prism of $1 \%$ is compared with the reference sample. The highest result was $17.1 \mathrm{Mpa}$ at the age of 28 days, and the result of the reference sample did not exceed $15 \mathrm{Mpa}$ at the same age. This corresponds to [23]. The same prism samples are used and applied to assess the bending strength recovery after healing for a period of 28 days. Whereas the recovered strength appeared to be the control sample and the sample containing the microcapsules, respectively (74.7\%, and 94.2\%), as shown in Figure 6 and this is evidence of the effectiveness of MC as a healing agent when compared to the control sample consistent with previous studies [24].

\subsection{Evaluation of Seal of Crack by Microscopy}

The cracks are observed with a microscope at 7 days of age and 28 days after healing with water. The healing values of the reference and sample $\mathrm{SiO}_{2} \mathrm{MC}$ after 28 days are shown in Figure 7, and the best decrease in the width of the cracks was in the sample of $\mathrm{SiO}_{2} \mathrm{MC}$. Likewise, Figure 8 shows the shape of the cracks that were detected by the microscope optical magnification that equals $40 \mathrm{X}$.

\subsection{SEM and XRD of Healed Samples}

An examination of SEM and XRD was performed in addition to seeing self-healing during microscopy, to see the changes in the microstructure.

In Figure 9-a, the results of the control sample containing $\mathrm{CH}$ and the gel $\mathrm{CSH}$ produced from the residual anhydrous cement are shown. It acts as a curing agent that closes very few cracks.

In Figure 9-c the sample containing the added capsules, the healing agent's calcium hydroxide, calcium silicate hydrate, and silica appear at the interface of the crack as a cure in the concrete paste that produces the CS [25].

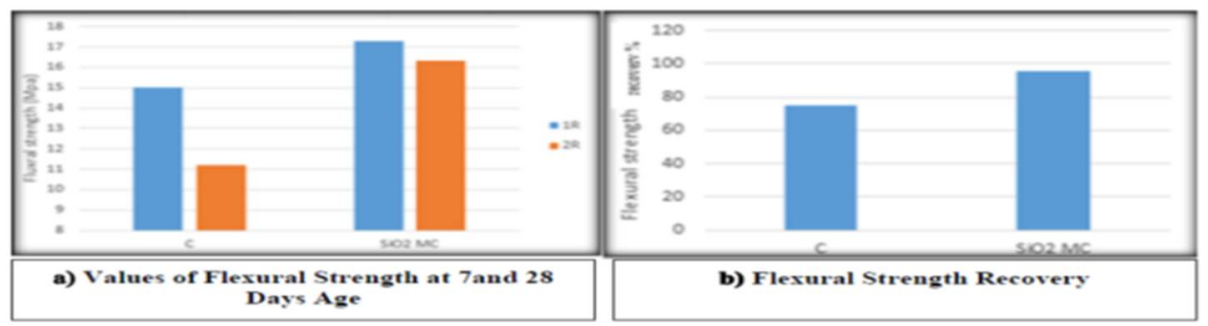

Figure 6: Flexural Strength



Figure 7: Healing values of the reference and MC sample



Figure 8: First-day Cracks before healing and at 7 and 28 days after healing 


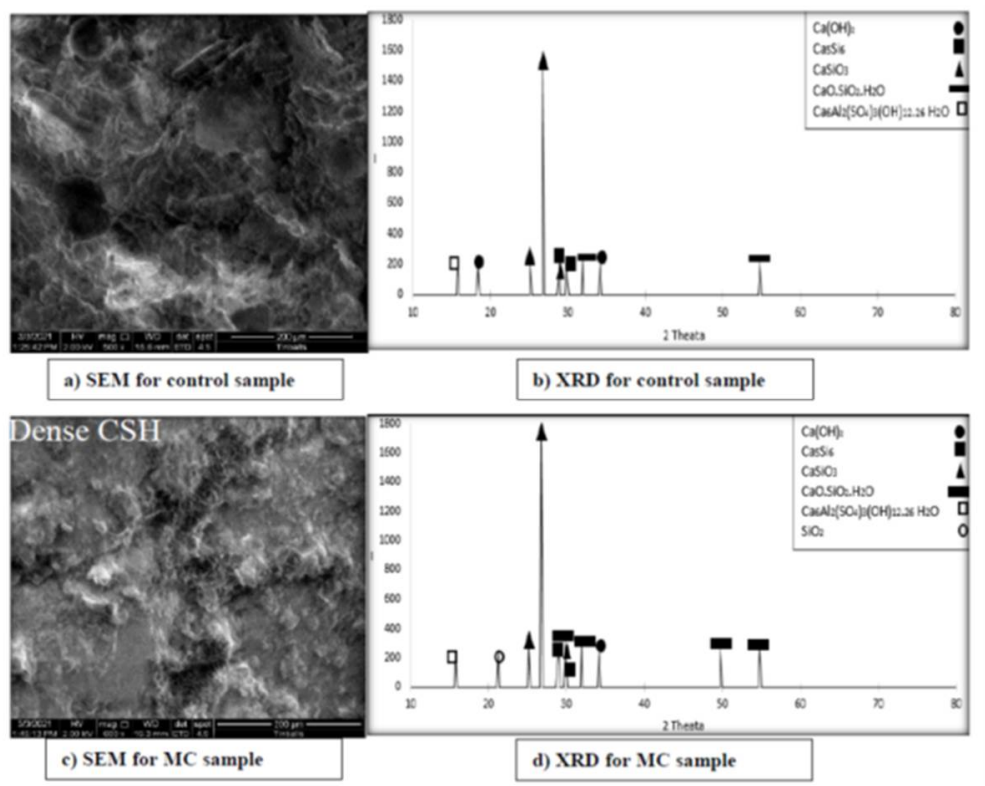

Figure 9: The XRD patterns and SEM images for the crack area of the healed samples

The XRD results also show the main components in concrete that gathered from faces of crack, as shown in Figure 9-b represented by $\left(\mathrm{Ca}(\mathrm{OH})_{2}, \mathrm{Ca}_{5} \mathrm{Si}_{6}, \mathrm{CaSiO}_{3}, \mathrm{CaO}_{2} \mathrm{SiO}_{2} \cdot \mathrm{H}_{2} \mathrm{O}\right.$, and $\left.\left.\mathrm{Ca}_{6} \mathrm{~A}_{12}\left(\mathrm{SO}_{4}\right)_{3}(\mathrm{OH})_{12} \cdot 26 \mathrm{H}_{2} \mathrm{O}\right)\right)$, and they were identical with JCPDS No. (04-0733, 45-1480, 43-1460,34.0002, and 41-1451), respectively, and that agrees with previous studies [26]. The peak of $\mathrm{SiO}_{2}$ is shown in Figure 9-d. $\mathrm{CSH}\left(\mathrm{CaO} \cdot \mathrm{SiO}_{2} \cdot \mathrm{H}_{2} \mathrm{O}\right)$ can be observed as healing agents that are abundant in Figure 9-d pooled on the crack face in contrast to the not appearance of peaks in the control sample. This is evidence of $\left(\mathrm{SiO}_{2}\right)$ resulting from the broken capsules spreading on the side of the crack interacting with $\mathrm{CH}\left(\mathrm{Ca}(\mathrm{OH})_{2}\right)$ to produce a condensed layer $(\mathrm{CSH})$. While virtually no peaks $\mathrm{CH}\left(\mathrm{Ca}(\mathrm{OH})_{2}\right)$ can be observed in the sample containing capsules compared to their appearance in the control sample. All other ingredients appeared without noticeable differences [27].

\section{Conclusion}

The effect of $\mathrm{SiO}_{2} \mathrm{MC}$ addition on the concrete mixture was considered in terms of its ability to self-repair concrete cracks. The physical and mechanical properties can be deduced from the research results. Several tests were performed, including compressive strength tests where the improvement ratios for (M1,M2, and M3) at 28 days were $(11.11$, and 22.22,5) $\%$ respectively, the density $(5.477,6.687$, and 0.59$) \%$, respectively, the water absorption $(66.6,70$, and 33$) \%$, respectively, the porosity of the concrete castings $(48.096,58.47$, and 44.636$) \%$, respectively, and the flexural strength of the best selected ratio, which showed improvement of (74.7\%, and $94.2 \%)$. Great healing ability through microscopy, and the ability to seal concrete cracks were observed at the age of 7 and 28 days, as the percentage of improvement of crack closure was (34.3, and 85.2) \%, respectively, which is better than the control sample. It achieved (6.8 and 42.9) \%, respectively. $\mathrm{SiO}_{2} \mathrm{MC}$ acts as a network that limits the content, size, microcrystals, and orientation of methane crystals.

\section{Author contribution}

All authors contributed equally to this work.

\section{Funding}

This research received no specific grant from any funding agency in the public, commercial, or not-for-profit sectors.

Data availability statement

The data that support the findings of this study are available on request from the corresponding author.

Conflicts of interest

The authors declare that there is no conflict of interest.

\section{References}

[1] M. Wu, B. Johannesson, M. Geiker, A review: Self-healing in cementitious materials and engineered cementitious composite as a self-healing material, Constr Build. Mater., 28 (2012) 571-583. https://doi.org/10.1016/j.conbuildmat.2011.08.086

[2] T. Qureshi ,A. Al-Tabbaa, Self-healing concrete and cementations materials, Adv. Funct. Mater., (2020). https://doi.org/10.5772/intechopen.92349

[3] X. Shang, J. Li, B. Zhan, Properties of sustainable cellular concrete prepared with environment-friendly capsule aggregates, J. Clean. Prod., 267 (2020) 122018. https://doi.org/10.1016/j.jclepro.2020.122018

[4] A. Heidari, D. Tavakoli, A study of the mechanical properties of ground ceramic powder concrete incorporating nano- $\mathrm{SiO}_{2}$ particles, Construction and Building Materials, 38 (2013) 255-264. https://doi.org/10.1016/j.conbuildmat.2012.07.110 
[5] P. Aggarwal, R. P. Singh, Y.Aggarwal, Use of nano-silica in cement-based materials-A review, Cogent .Eng., 2 (2015). https://doi.org/10.1080/23311916.2015.1078018

[6] B. Dong, G. Fang, W. Ding, Y. Liu, J. Zhang, N. Han , F. Xing, Self-healing features in Cementitious material with ureaformaldehyde/epoxy microcapsules, Constr. $\quad$ Build. $\quad$ Mater. $106 \quad$ (2016) 608 617. https://doi.org/10.1016/j.conbuildmat.2015.12.140

[7] P. Minnebo, G. Thierens, G. Valck, K. Tittelboom, N. Belie, D. Hemelrijck , E. Tsangouri, A novel design of autonomously healed concrete: towards a vascular healing network, Mater., 21. https://doi.org/10.3390/ma10010049

[8] K. Tittelboom, E. Tsangouri, D. Hemelrijck N. Belie, The efficiency of self-healing concrete using alternative manufacturing procedures and more realistic crack patterns, Cem. Concr. Compos., 57 (2014) 4-19. doi:10.1016/j.cemconcomp.2014.12.002

[9] B. Dong, Y. Wang, G. Fang, N. Han, F. Xing, Y. YuanL, Smart releasing behavior of a chemical self-healing microcapsule in the stimulated concrete pore solution, Cem. Concr. Compos., 56 (2015) 46-50. https://doi.org/10.1016/j.cemconcomp.2014.10.006

[10] B. Hilloulin, K. V. Tittelboom, E. Gruyaert, N. D. Belie, A. Loukili, Design of polymeric capsules for self-healing concrete, Cem. Concr. Compos., 55 (2015) 298-307. https://doi.org/10.1016/j.cemconcomp.2014.09.022

[11] K. Mei, X. Cheng, L. Zhang, X. Guo, J. Zhuang, Ch. Zhang, Self-healing mechanism of Zn enhanced cement stone: an application for sour natural gas field, Constr. Build. Mater., $227 \quad$ (2019) $1-10$. https://doi.org/10.1016/j.conbuildmat.2019.08.032

[12] W. Du, J. Yu, B. He, Y. He, P. He, Y. Li, Q. Liu, Preparation and characterization of nano $\mathrm{SiO}_{2} / \mathrm{paraffin} / \mathrm{PE}$ wax composite shell microcapsules containing TDI for self-healing of cementitious materials, Constr. Build. Mater., 231 (2020) 1-10. https://doi.org/10.1016/j.conbuildmat.2019.117060

[13] Testing concrete, method of normal curing of test specimens (20 ${ }^{\circ} \mathrm{C}$ method), BS (1983) 1881-111.

[14] Testing concrete, method for determination of compressive strength of concrete cubes, BS (1983), 1881-116.

[15] N. Shi, Y. Chen , Z. Li, Crack risk evaluation of early age concrete based on the distributed optical fiber temperature sensing, Adv. Mater. Sci. Eng., (2016) 1-12. https://doi.org/10.1155/2016/4082926

[16] Standard test method for density, absorption, and voids in hardened concrete, C: 642, ASTM (2013).

[17] B .Mohammad, A. Joshaghani , F .Althoey, Nano- $\mathrm{SiO}_{2}$ contribution to mechanical, durability, fresh and microstructural characteristics of concrete: A review, Constr. Build. Mater., $181 \quad$ (2018) $27-41$. https://doi.org/10.1016/j.conbuildmat.2018.05.266

[18] W. Du, J. Yu , Y. Gu, Y. Li, X. Han, Q. Liu, Preparation and application of microcapsules containing toluene-diisocyanate for self-healing of concrete, Constr. Build. Mater., $202 \quad$ (2019) $762-769$. https://doi.org/10.1016/j.conbuildmat.2019.01.007

[19] A. Z. Dahesh, F. M. Othman, A. A. Abdul-hamead, Influence of microfibers additive on the self-healing, J. Eng. Technol., 39 (2021) 104-115. https://doi.org/10.30684/etj.v39i1A.1581

[20] A. A. Abdul Hamead, F. M .Othman, R .K. Mohammed, Investigation the effect of nano-particles and recycling mortar additives on physical and mechanical properties of concrete, J. Eng. Technol., 36 (2018) 295-303. https://doi.org /10.30684/etj.36.3a.8

[21] D. M. Abdullah, A. A. Abdulla Hameed, F. M. Othman, Preliminary investigation on G cement modified by nanopowder, J. Eng. Technol., 38 (2020) 143-151. https://doi.org/10.30684/etj.v38i2A.93

[22] A. A. Abdulla Hameed, F. M. Othman, S. Ibrahim, Studying the effect of nano additives and coating on some properties of cement mortar mixes, J. Eng. Technol., 34 (2016) 553-566. https://doi.org/10.30684/etj.34.3a.10

[23] H. Castaneda, M. Hassan, M. Radovic, J. Milla, A. Karayan, Self-healing microcapsules as concrete aggregates for corrosion inhibition in reinforced concrete, Tran-SET, 17CLSU08, (2018) 9-65.

[24] W. Li, Z. Jiang, Z. Yang, Acoustic characterization of damage and healing of microencapsulation based self-healing cement matrices, Cem. Concr. Compos., 84 (2017) 48-61. https://doi.org/10.1016/j.cemconcomp.2017.08.013

[25] A. Kanellopoulos, P. Giannaros, D. Palmer, A. Kerr, A. Al-Tabbaa, Polymeric microcapsules with switchable mechanical properties for selfhealing concrete: synthesis, characterization and proof of concept, Smart .Mater .Struct., 26 (2017) 123128. https://doi.org/10.1088/1361-665X/aa516c

[26] P. Giannaros, A. Kanellopoulos, A. Al-Tabbaa, Sealing of cracks in cement using microencapsulated sodium silicate, Smart. Mater. Struct., 25 (2018) 1-12. https://doi.org/10.1088/0964-1726/25/8/084005

[27] A. Al-Tabbaa, C. Litina, P. Giannaros, A. Kanellopoulos, L. Souza, First UK field application and performance of microcapsule-based self-healing concrete, Constr. Build. Mater., $208 \quad$ (2019) 669-685. https://doi.org/10.1016/j.conbuildmat.2019.02.178 